\title{
Survival analysis of chronic kidney disease patients with hemodialysis
}

\author{
Kuwat Susanto', Asiandi ${ }^{2}$ \\ 1 Nursing Department Students, Faculty of Health Sciences, University of Muhammadiyah Purwokerto, Indonesia \\ 2 Department of Medical Nursing Surgery Nursing Faculty of Health Sciences Muhammadiyah University Purwokerto, \\ Indonesia
}

\begin{tabular}{l} 
ARTICLE INFO \\
Article history: \\
Received: August 9, 2020 \\
Revised: August 20, 2020 \\
Accepted: August 30, 2020 \\
\hline
\end{tabular}

Keywords:

Survival analysis; Chronic Kidney Disease; hemodialysis

\begin{abstract}
The incidence of Chronic Kidney Disease (CKD) is increasing every year. The prevalence of CKD patients in Indonesia is $0.2 \%$. One of the management of CKD is hemodialysis. The benchmark of success in hemodialysis therapy in extending the life of the patient is a survival rate. Through this survival rate, it will be visible to see the duration of the patient can survive. Objective: This study aimed to determine the factors which affected the survival time of Chronic Kidney Disease patients undergoing hemodialysis in Banyumas Regional Hospital. This study implemented an observational analytic design. This research type was a retrospective cohort. This study involved 275 respondents selected through simple random sampling technique. The setting of the study was in the Hemodialysis Room of Banyumas Regional Hospital. Research variables were tested by Kaplan meier method. The analysis indicated that the occupation and vascular access significantly affect the survival rate of patients with the Chronic Kidney disease. The result of the significance (p-value) was smaller than 0.05.There is a correlation between factors that affected the survival rate and the time of life resistance of CKD patients undergoing hemodialysis at Banyumas Regional Hospital, which are occupation and vascular access.
\end{abstract}

This work is licensed under a Creative Commons Attribution 4.0 International License.

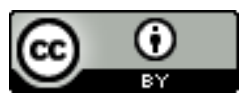

\section{Corresponding Author:}

Kuwat Susanto,

Faculty of Health Sciences, University of Muhammadiyah Purwokerto,

229 Soepardjo Roestam Road, Purwokerto 53186, Indonsia.

Email: kuwatsusanto@gmail.com

\section{INTRODUCTION}

The kidneys have an important role in the human body to maintain the volume and distribution of fluids, but if the kidneys fail to do so, the person will need immediate care and treatment [1]. Chronic Kidney Disease (CKD) is a chronic disease that progressively damages the kidneys so that it disrupts the body's fluid and electrolyte balance which affects all body systems. Data on the growth of the number of CKD sufferers in the world in 2013 increased by 50\% from the previous year [2]. The global incidence of kidney failure is more than 500 million people and about 1.5 million people who have to undergo hemodialysis [3]. The incidence of CKD has increased from year to year and in America the incidence rate has increased by 50\% in 2014 and every year 200,000 Americans undergo hemodialysis [4]. In Indonesia, the number of CKD sufferers undergoing hemodialysis reaches $6.2 \%$ or around 104,000 people of the Indonesian population. The prevalence of CKD sufferers in Indonesia is $0.2 \%$. Statistical data from the Indonesian Nephrology Association [5] states that the number of kidney failure patients in Indonesia has continued to increase from year to year. In 2017, the total number of patients was 77,892 . The number of new patients continues to increase as the hemodialysis units increase. The age distribution in 2017 in the age group 1-14 years was $0.32 \%$, aged 35-44 years was $14.23 \%$. The largest proportion is still in the 45-65 years age category. Patients aged less than 25 years contributed $2.64 \%$ to active patients. 
Patients undergoing hemodialysis therapy have a very high mortality rate compared to the general population. The measure of success in hemodialysis therapy in extending a patient's life is the survival rate. Through this survival rate, it will be known how long the patient can survive. In a study conducted in Ethiopia on 91 hemodialysis respondents, it was found that survival rate in three months was $61.5 \%$, while for one year and five years it was $42.1 \%$ and $14.8 \%$ [6]. The death rate due to hemodialysis is not purely the cause of hemodialysis, but many factors are suspected to influence it. Factors that affect the survival of CKD patients include age, nutritional status, adequate hemodialysis, renal replacement therapy methods and the etiology of renal failure [7]. The factors that affect the reduction of the survival rate of hemodialysis patients are hypertension, inadequate vascular access and diabetes mellitus, while patients aged $>60$ years, malnutrition, experiencing hypoalbuminemia, anemia and the presence of cardiovascular disease have a low survival rate [8].

Banyumas Regional General Hospital is a hospital that accepts many hemodialysis patients in the Banyumas residency. The number of patient visits for hemodialysis therapy daily reached 68 visits. Meanwhile, the number of monthly visits reaches 1200 - 1700 visits. Meanwhile, the total number of patients undergoing elective hemodialysis in the hospital's hemodialysis unit was 189 people in March 2019. The average patient underwent hemodialysis 2 times a week for 4-5 hours per visit. The information regarding the survival of CKD patients undergoing hemodialysis and the large number of visits by hemodialysis patients at the Banyumas Regional General Hospital, triggers the researchers' interest to conduct a research on the survival of CKD patients undergoing hemodialysis at the Banyumas Regional General Hospital.

\section{RESEARCH METHOD}

This study used an observational analytic design, which means a research without intervening or treating the object under study. This type of study is a retrospective cohort, which is to determine the survival rate of CKD patients undergoing hemodialysis with a retrospective time dimension. The location of observations was carried out in the Banyumas Hospital Hemodialysis Room from 01 October 2019 to 31 December 2109. The population of CKD patients who started hemodialysis at Banyumas Hospital from 01 January 2014 to 31 December 2018 were 881 people. The sample used in this study were all CKD patients who started hemodialysis therapy starting from January 1, 2014 to December 31, 2018 with the following inclusion and exclusion criteria Inclusion Criteria is CKD patients who started to undergo hemodialysis at Banyumas Regional Hospital from January 1, 2014 to December 31, 2018 and Exclusion Criteria is Patients with missing or incomplete medical records.

Data from all eligible and complete patients were collected from medical records over a span of 5 years. The sample size calculation used is using the Slovin formula which is simple and easy to use. Of the 881 people in a population, we can determine the minimum sample to be studied. When rounded, the minimum sample size of 881 populations at a margin of error of $5 \%$ is 275 . In the formula above, the assumption used is that all subjects are followed from the first time they start hemodialysis therapy until death occurs or disappears from observation. Sampling was done by using simple random sampling technique. Samples were randomized from a list of 881 patients using a numeric random generator. The sample selection was randomized to obtain the required number of samples, namely 275 samples.In this study, the variables used are:

Independent variables are variables that affect or cause the emergence or change of the dependent variable. The independent variables in this study are individual characteristic factors, socio-economic factors, treatment factors, comorbidities and nutritional status. The dependent variable is the variable that is influenced by the independent variable. The dependent variable in this study is the length of time of survival of CKD patients in the medical records from January 1, 2014 to December 31, 2018.

The data to be used in this study came from secondary data, namely the medical record documents of hemodialysis patients at Banyumas Regional Hospital. Then the data will be analyzed in stages, namely univariate analysis, bivariate analysis and multivariate analysis. Univariate analysis is describing each of the independent variables and the dependent variable using a frequency distribution table and performing the $\mathrm{PH}$ (proportional hazard) assumption test using the Kaplan Meier method. In the Kaplan Meier method, it is known that if the lines on the survival chart do not intersect, it means that the PH assumption is met. On the other hand, if the lines on the survival chart intersect, the $\mathrm{PH}$ assumption is not fulfilled. Bivariate analysis was carried out to see the relationship between variables of age, gender, marital status, haemodialysis frequency, hypertension status and diabetes mellitus status on survival time using the HR (Hazard Ratio) value which obtained by cox regression analysis.

\section{RESULT AND DISCUSSION}

The description of respondent characteristics based on age, gender, education, occupation, marital status, hemodialysis frequency, vascular access, family support, anemia, hypertension, diabetes mellitus, bone disease, BMI, nutritional status and health insurance ownership, can be seen from the following table : 
The results of age factor descriptive statistics were presented in Chronic Kidney Disease (CKD) who underwent hemodialysis aged 55.9 years with a standard deviation of 12.292. The oldest patient was 85 years old and the youngest was 22 years old. The majority of CKD patients undergo hemodialysis twice/week. Patients who did hemodialysis once/week were $2.2 \%$ and $97.8 \%$ twice/week. Gender of CKD patients who underwent hemodialysis were almost the same, namely 141 and 134 people. The majority of CKD patients undergoing hemodialysis are married patients, $89.9 \%$. Based on hypertension status, information is that the majority of CKD patients undergoing hemodialysis have hypertensive complications. Based on their Diabetes Status, CKD patients undergoing hemodialysis do not have diabetes complications. The nutritional status of CKD patients undergoing hemodialysis was normal with a percentage of $68.4 \%$. Mostly used vascular access with femoral access, namely $80.7 \%$. Anemia status $88.0 \%$ of patients did not suffer from anemia. The composition of work status is illustrated by the largest number of unemployed workers, namely $41.1 \%$, this is because female patients undergoing hemodialysis are housewives. The majority of the payment methods used by BPJS were $98.2 \%$. The percentage of education level is dominated by elementary school graduates with 147 or $53.5 \%$ patients.

In the survival test of the Kaplan Meier method, it was found that the probability of survival with the median survival time was 462 days. The median estimate of survival time in patients aged 17-25 years was 715 days. For ages 26-35 years it is 747 days and so on until the age is over 65 years, which is 341 days. The log rank test shows no significant difference with a $\mathrm{p}$ value of 0.337 . The gender in this study was categorized into 1 for men and 2 for women. The survival curve for male patients is above the survival curve for female patients, so it is suspected that there is a difference in the survival time for CKD patients in undergoing hemodialysis based on gender variables. Test Log Rank Variable Gender Log Rank P-value 0.545. This means that the survival time for renal failure patients undergoing hemodialysis did not differ significantly based on sex.

Marital status is one of the factors that is thought to affect the survival time of CKD patients undergoing hemodialysis. In this study, the marital status was categorized into 4, namely 1 for married, 2 for unmarried, 3 for divorced and 4 for widowed. Figure 4.3 shows that the patient survival curve based on marital status obtained estimates for patients who have been married 536 days, 715 days unmarried, 1.101 divorced and 266 days divorced. The result of the p-value is 0.423 which is greater than $\alpha$, then it results in a failure to reject $\mathrm{H} 0$. This means that the survival time of CKD patients undergoing hemodialysis does not differ significantly based on marital status.

Estimated median survival time for CKD patients with elementary education level was 462 days, 559 days for middle school level, 840 days for high school level, 1487 days of D1 (diploma), 536 days of D2, 753 days of D3 and 421 days of S1 (undergraduate). In this study, the results obtained P value of 0.580 which means that it does not differ significantly based on educational status. The estimated median survival time for CKD patients with payment status using BPJS is 536 days and for payments using private or public use is 309 days. The log rank test shows that there is no significant difference based on payment status with p value 0.119.

Table 1. Estimated median survival time for employment status

\begin{tabular}{ccccc}
\hline Occupation & \multicolumn{4}{c}{ Median } \\
& Estimation & Error Standard & 95\% CI & p-value \\
\hline Unemployed & 529 & 122,929 & $288,060-769,960$ & \\
Factory workers & 715 & 223,625 & $276,695-1153,305$ & \\
Farmers & 343 & 56,435 & $232,388-456,612$ & 0,593 \\
Private Employment & 497 & 61,309 & $378,833-617,167$ & \\
Civil Servants & 711 & 255,839 & $205,556-1212,444$ & \\
Retiree & 840 & 358,644 & $137,057-1542,943$ & \\
\hline
\end{tabular}

Table 2. Estimated median survival time versus hemodialysis frequency

\begin{tabular}{ccccc}
\hline Hemodialysis Frequency & \multicolumn{4}{c}{ Median } \\
\cline { 2 - 5 } & Estimastion & Error Standard & 95\% CI & p-value \\
\hline 1 time & 1484 & 1030,449 & $0,000-3503,679$ & 0,593 \\
2 times & 529 & 81,952 & $368,373-689,627$ & \\
\hline
\end{tabular}

Table 3. Estimated median survival time for anemia status

\begin{tabular}{ccccc}
\hline Anemia Status & \multicolumn{4}{c}{ Median } \\
& Estimation & Error Standard & $\mathbf{9 5 \%}$ CI & p-value \\
\hline Yes & 397 & 96,010 & $208,820-585,180$ & 0,150 \\
No & 554 & 95,041 & $367,720-740,280$ & \\
\hline
\end{tabular}


Table 4. Estimated median survival time for vascular access

\begin{tabular}{ccccc}
\hline Vascular & & \multicolumn{2}{c}{ Median } & \\
Access & Estimation & Error Standard & 95\% CI & p-value \\
\hline Femoral & 554 & 89,687 & $378,214-729,786$ & \\
AV- Shunt & 451 & 198,558 & $61,825-840,175$ & 0,085 \\
Double lumen & 389 & 62,823 & $265,868-512,132$ & \\
\hline
\end{tabular}

Based on the Diabetes Factors, Diabetes Status is also thought to affect the survival time of CKD patients undergoing hemodialysis. In this study, the status of diabetes mellitus was categorized into 2, namely 1 for those with diabetes complications and 2 for patients without diabetes complications. Figure 4.9 Kaplan Meier Survival Curve Based on Diabetes Status, there is a blue line showing patients without diabetes complications and a green line showing patients with diabetes complications. Figure 4.9 shows that the survival curve for patients without complications of diabetes is above the survival curve for patients with complications, so it is suspected that there is a difference in the survival time of CKD patients undergoing hemodialysis based on the diabetes status variable. To support this hypothesis, a log rank test was performed and the p-value was 0.535. This means that the survival time of CKD patients undergoing hemodialysis does not differ significantly based on diabetes status.

Hypertension is one of the factors that is thought to affect the survival time of CKD patients undergoing hemodialysis. In this study, the hypertension status was categorized into 2 , namely 1 for those with hypertension complications and 2 for patients without hypertensive complications. Based on Hypertension Status In Figure 4.10, there is a blue line that shows patients who do not have hypertension complications and a green line that shows patients with hypertensive complications. The log rank test shows the p-value of 0.083 . This means that the survival time of CKD patients undergoing hemodialysis does not differ significantly based on hypertension status. The estimated median survival time in CKD patients with poor nutritional status was 367 days, normal nutritional status was 559 days, over-nutrition status was 497 days and for obese patients it was only 166 days. The log rank test showed no significant difference based on nutritional status with a $\mathrm{p}$ value of 0.079 .

The cox regression model includes variables that affect survival in patients with chronic kidney disease. Then the final cox regression model is as follows:

$h(t, x)=h o(t) \cdot e^{-(b 1 \times 1+b 2 x 2+\cdots b i x i)}$

$h(t, x)=$

$-(0,559 *$ private employee $+0,573 *$

ho(t).e AV shunt vasculare access)

The results above can be interpreted as Exp (B) as the Hazard Ratio (HR) of one variable controlled by another variable. Where the results are as follows: There is a relation between the type of work and the survival of chronic kidney disease patients undergoing hemodialysis. HR value $=1.749(95 \% \mathrm{CI})$, p value 0.042 . Patients with private employment have a risk of dying 1,749 times (75\%) compared to patients who do not work. There is a relationship between vascular access and survival in chronic kidney disease patients undergoing hemodialysis. HR value $=1.773(95 \% \mathrm{CI})$, p value 0.021 . Patients with vascular access to AV shunt, had a risk of death 1.773 times $(77 \%)$ compared with femoral vascular access.

\section{CONCLUSION}

The things that can be observed on Chronic Kidney Disease (CKD) patients undergoing hemodialysis at Banyumas Regional Hospital are age, sex, marital status, educational status, employment status, health insurance, hemodialysis frequency, anemia status, vascular access, diabetes militus status, hypertension status and nutrition. Significant influencing factors were the variable of private employment status and AV Shunt vascular access.

\section{REFERENCES}

[1] A. Muttaqin and K. Sari, Gangguan gastrointestinal: Aplikasi asuhan keperawatan medikal bedah, Salemba Medika: Jakarta, 2011.

[2] V. A. Luyckx, M. Toneli and J. W. Stanifer,, "The global burden of kidney disease and the sustainable development goals," p. 414-422, 2018. 
[3] Yuliana, "Hubungan dukungan keluarga dengan kepatuhan pembatasan cairan pada pasien gagal ginjal kronik dengan terapi hemadialisis di RS PKU Muhammadiyah Yogyakarta," Sekolah Tinggi Ilmu Kesehatan 'Aisyiah, Yogyakata, 2015.

[4] R. Widyastuti, W. R. Butar-Butar and R. Bebasari, "Korelasi lama menjalani hemodialisis dengan indeks massa tubuh pasien gagal ginjal kronik di RSUD Arifin Achmad Provinsi Riau pada bulan Mei tahun 2014," Jom Fakultas Kedokteran, vol. 1, no. 2, pp. 1-12, 2014.

[5] PERNEFRI, 10th report of Indonesian Renal Registry 2017., Jakarta, 2017.

[6] T. Shibiru, E. K. Gudina, B. Habte and A. Deribew, "Survival patterns of patients on maintenance hemodialysis for end stage renal disease in Ethiopia : summary of 91 cases," 2013.

[7] Mousavi, S. B. Seyed and A. Soleimani, "Epidemiology of end-stage renal disease in Iran," review article, vol. 25, no. 3, p. 697-702, 2014.

[8] J. Valdivia, C. Gutiérrez, J. Treto and E. Delgado, "Prognostic factors in hemodialysis patients," experience of a Havana Hospital, pp. 11-15, 2013. 